\title{
SARS-CoV-2: A critical review of preventive and control measures in the context of the virus' characteristics
}

\section{Review scientific article}

Received: 1. 12. 2020

Accepted: 14. 12. 2020

Published: 31. 12. 2020
${ }^{1}$ University of Ljubljana, Faculty of Health Sciences, Zdravstvena pot 5, 1000 Ljubljana, Slovenia

${ }^{\text {la }}$ Master student of Sanitary Engineering at University of Ljubljana, Faculty of Health Sciences, Zdravstvena pot 5, 1000 Ljubljana, Slovenia

* Corresponding author

Assist. Prof. Andrej Ovca

University of Ljubljana, Faculty of Health Sciences, Zdravstvena pot 5, 1000 Ljubljana, Slovenia

E-mail: andrej.ovca@zf.uni-lj.si

(C) 2020 Manca Alič, Andrej Ovca. This is an open access article licenced under the Creative Commons Attribution NonCommercial-NoDerivs license as currently displayed on http:// creativecommons.org/licenses/by-nc$\mathrm{nd} / 4.0 \%$.

\author{
Manca ALIČ ${ }^{1 a}$, Andrej OVCA ${ }^{1 *}$
}

\section{ABSTRACT}

The year 2020 has been marked by the novel coronavirus, named Severe Acute Respiratory Syndrome 2 (SARS-CoV-2), which causes coronavirus disease COVID-19. The World Health Organization (WHO) declared a global pandemic on the $11^{\text {th }}$ of March 2020 due to the spread of this very contagious virus throughout the world. Since the outbreak, we have gained many insights about the virus, its presence and persistence in the environment and its possible and most common transmission routes. Such knowledge about the virus is invaluable for establishing effective preventive and control measures (also referred to as Non-Pharmaceutical Interventions (NPIs)) that have become a key to tackling this pandemic in the absence of a SARS-CoV-2 vaccine. In this review, we discuss five main groups of NPIs: 1) ventilation, 2) cleaning and disinfection, 3) hand hygiene, 4) physical distancing, and 5) protective masks. We explore their shortcomings and potential negative consequences that might occur as unwanted side effects.

Key words: SARS-CoV-2; transmission routes; presence; persistence; preventive measures; NPIs

\section{POVZETEK}

Leto 2020 je pomembno zaznamovano z novim korona virusom, imenovanim akutni respiratorni sindrom 2 (SARS-CoV-2), ki povzroča korona-virusno bolezen COVID-19. Zaradi hitrega in obsežnega širjenja je Svetovna Zdravstvena Organizacija (SZO) 11. marca 2020 razglasila pandemijo. Od pojava bolezni smo pridobili veliko informacij o virusu, njegovi obstojnosti v okolju ter o možnih poteh prenosa. Pridobljeno znanje o karakteristikah SARS-CoV-2 je ključno za vzpostavitev učinkovitih preventivnih ukrepov (angl. Non-Pharmaceutical Interventions), ki so ključni za obvladovanje te pandemije ob odsotnosti cepiva. Članek obravnava pet ključnih preventivnih ukrepov: 1) prezračevanje, 2) čiščenje in dezinfekcija, 3) higiena rok, 4) fizična razdalja in 5) zaščitne maske. Ob pregledu študij smo raziskali njihove omejitve ter identificirali možne negativne posledice.

Ključne besede: SARS-CoV-2; poti prenosa; prisotnost; obstojnost; preventivni ukrepi 
Due to the rapid and global spread of SARS-CoV-2, the WHO declared the outbreak of a global pandemic on the $11^{\text {th }}$ of March 2020, after declaring a public health emergency in January.

Unless there is a vaccine available, some of existing viruses are best controlled with appropriate preventive and control measures, which are also referred to as NonPharmaceutical Interventions.

\section{INTRODUCTION}

On the $31^{\text {st }}$ of December 2019, the Wuhan Municipal Health Commission in China reported a cluster of cases of pneumonia in Wuhan, which is located within Hubei Province. On the $13^{\text {th }}$ of January, the same pneumonia was detected in Thailand [1]. However, a recent study by Apolone et al. [2] shows that the virus had been present in Italy since September 2019. The authors of the study found SARS-CoV-2 receptorbinding domain (RBD)-specific antibodies in blood samples of asymptomatic lung cancer screening trial participants. This finding shows that the virus was circulating among asymptomatic participants in the months before it was identified in China. Later, the World Health Organization (WHO) announced an official name for the virus responsible for the above-mentioned pneumonia cases; Severe Acute Respiratory Syndrome Coronavirus 2 (SARS-CoV-2) (previously known as '2019 novel coronavirus') and the disease it causes; coronavirus disease 2019 (COVID-19) [3].

Due to the rapid and global spread of SARS-CoV-2, the WHO declared the outbreak of a global pandemic on the $11^{\text {th }}$ of March 2020, after declaring a public health emergency in January [1]. At the time that the present paper is being prepared, the virus has spread to 215 countries, in which over 40 million people have been infected, and over 1 million of the infected people died since its appearance to mid-October 2020 [4].

This is not the first time a coronavirus has caused extensive health problems. Coronaviruses (CoVs) are a large group of viruses that usually spread among animals. However, some can infect people and cause diseases ranging from a mild cold to Severe Acute Respiratory Syndrome (SARS). In 2002, SARS emerged in China and, in about eight months, spread to 33 countries, causing over 8,000 infections [5]. Another recent pandemic, also caused by a coronavirus, was Middle East Respiratory Syndrome Coronavirus (MERS-CoV), first detected in Saudi Arabia in 2012. Since then, it has been identified in 27 countries, with the most cases (80\%) reported in its country of origin [6].

Unless there is a vaccine available, some of existing viruses are best controlled with appropriate preventive and control measures, which are also referred to as Non-Pharmaceutical Interventions (NPIs). To establish effective and not overly excessive NPIs, we have to understand how the virus acts, which includes knowing where the virus is present and how persistent it is in the environment. Furthermore, we need to know the possible and the most common transmission routes for this virus to spread. Once we have this information about the virus's characteristics, we can guide people with the most appropriate NPIs specific for a certain virus, in our case SARS-CoV-2. The aim of this review is therefore to 1) summarise existing knowledge about transmission routes of SARS-CoV-2, 2) collect information about its presence and persistence in the environment 3) outline existing NPIs that were adopted during this pandemic to control the spread of SARS-CoV-2, and 4) critically review described NPIs in context of their advantages, shortcomings, and possible consequences they might bring. 


\section{TRANSMISSION ROUTES}

The number of possible transmission routes varies between infectious agents [7]. SARS-CoV-2 tends to be highly infectious, which could relate to the ability of an infected individual to shed infective particles even when they have no symptoms. Such shedding of the virus can happen at three phases of SARS-CoV-2 infection by 1) an infected person before showing symptoms (pre-symptomatic), 2) an infected person that is not showing symptoms (asymptomatic), and 3) an infected person after recovery who can still shed virulent particles (post-symptomatic) [8]. The duration of the above-mentioned phases differs from one phase to the other; the pre-symptomatic phase lasts approximately 2-3 days, asymptomatic 4-11 days, and postsymptomatic 11-14 days. Consequently, people can become infected if they are in proximity of an infected individual that may never even know they are/were infected and able to transmit the virus [8]. Castaño et al. [9] reported that virus shedding may happen when an infected person is sneezing, coughing, talking, spitting, singing or exhaling (i.e., that respiratory secretions are being released from the infected individual). This secretion contains infectious particles that can be categorized into droplets or aerosols based on their diameter. Droplets have a diameter larger than $5 \mu \mathrm{m}$, while aerosols are smaller than $5 \mu \mathrm{m}$ in diameter.

SARS-CoV-2 can be transmitted through many different routes or even combinations of them (Figure 1). Unfortunately, we only have limited information about the specific transmission routes of SARS-CoV-2, which, consequently, makes it more difficult to accept efficient yet not excessive NPIs to confine the spread of the virus. The WHO [10] reported that it is predominantly spread with direct contact amongst people (i.e., humanto-human). However, they described many possible modes of transmission, including contact, droplet, airborne, fomite, faecal-oral, bloodborne, mother-to-child and animal-to-human transmission.

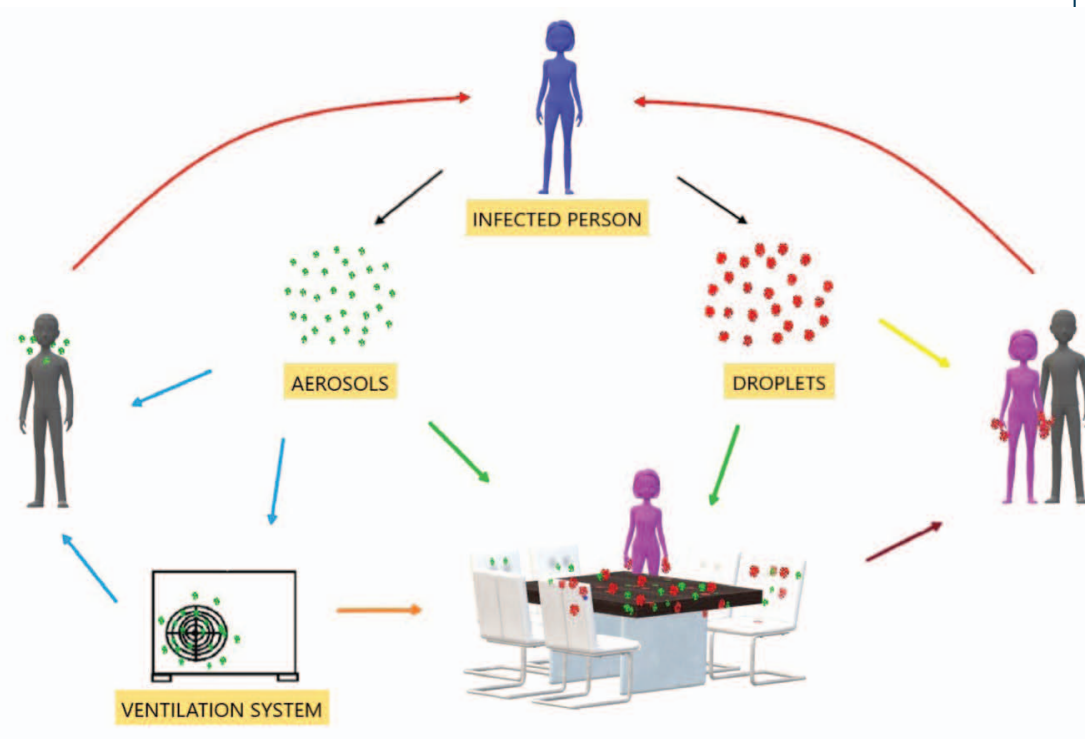

SARS-CoV-2 tends to be highly infectious, which could relate to the ability of an infected individual to shed infective particles even when they have no symptoms.

SARS-CoV-2 can be transmitted through many different routes or even combinations of them.

Figure 1.

Transmission routes of SARS-CoV-2 
The meaning of human-to-human

transmission is the immediate movement of an infectious agent to a susceptible host. Such movement is possible through 1) direct contact (touching, kissing, biting, and sexual intercourse) with an infected individual and 2) droplet dispersed by an infected person that reach the facial membranes (eyes, nose, or mouth) of susceptible individuals.

Fomites can be formed when an infected person emits the virus in the form of respiratory droplets or secretions. These emitted droplets are too heavy to be airborne, and they thus land on the objects and surfaces surrounding the infected person.
Li et al. [11] analysed the data of the first 425 confirmed cases in order to determine epidemiologic characteristics of SARS-CoV-2. They found evidence that the virus has been present since the middle of December 2019 and was transmitted human-to-human with close contact. They also estimated a reproductive number $\left(R_{0}\right)$ of approximately 2.2 , which means every infected individual infected another 2.2 persons. $R_{0}$ helps us predict the epidemic. As long as $R_{0}$ is greater than 1 , the number of new infections amongst people will rise. In contrast, when $R_{0}$ is less than 1 , it implies that the epidemic is being controlled.

An important fact about SARS-CoV-2 is its infectious dose. Thus far, no experimental studies have provided information about the exact SARSCoV-2 infectious dose for humans, neither in droplets nor in aerosols. Furthermore, no studies have been published estimating viral loads in fomites. However, in a recent study by Basu [12], the infectious dose was estimated to be 300 infectious particles. The estimation was made with a computational characterization of inhaled droplet transport in the upper airway. The aforementioned authors also suggested that the infectious dose is probably low, considering the rapid spread of the virus.

\section{Direct transmission (human-to-human)}

The meaning of human-to-human transmission is the immediate movement of an infectious agent to a susceptible host. Such movement is possible through 1) direct contact (touching, kissing, biting, and sexual intercourse) with an infected individual and 2) droplet dispersed by an infected person that reach the facial membranes (eyes, nose, or mouth) of susceptible individuals (Figure 1). It is often limited to a distance of $1 \mathrm{~m}$ or less from the source [7]. What makes this transmission route so probable is the large viral load that can be emitted when an infected individual sheds the virus. Also, since it is a human-to-human transmission, the emitted viral load spends less time outside of a host. This is in contrast to other routes of transmission [9].

\section{Indirect contact with fomites (fomite transmission)}

Castaño et al. [9] summarised that fomites are objects or surfaces contaminated with an infectious agent. Fomites can be formed when an infected person emits the virus in the form of respiratory droplets or secretions. These emitted droplets are too heavy to be airborne, and they thus land on the objects and surfaces surrounding the infected person (Figure 1). Once a person touches fomites (e.g., doorknobs, shopping cart, stair railing, elevator buttons, etc.) and then touches their mouth, nose, or eyes, they can become infected [13]. On some materials, viruses can remain viable for hours or even days, especially if environmental conditions (i.e., temperature and humidity) are favourable. Another possible but less probable way of fomites forming is with aerosols settling on surface or objects [9]. A combination of indirect and direct transmission is also possible when a person catches the virus through fomites and spreads it with close contact, like ordinary handshaking [10] (Figure 1). 


\section{Airborne transmission}

The WHO described airborne transmission as the spread of an infectious agent caused by the dispersal of droplet nuclei, also referred to as aerosols [10]. Castaño et al. [9] highlighted that a virus in an aerosol form can directly cause an infection by reaching an individual's respiratory tract or indirectly through settling on surfaces or objects forming fomites (Figure 1). The difference between droplets and aerosols is not only related to their size but also the distance they can travel, and the time they can remain in the air. Droplets usually spread and fall within a radius of 1-2 $\mathrm{m}$ from their source, all within seconds from the moment they originated. Aerosols, in contrast, can stay present in the environment for minutes or even hours while carrying their viral load and travel over a long distance (i.e., 10 metres and more). Morawska and Cao [14] discussed the possibility of aerosols being transported via ventilation systems (Figure 1). Such characteristics of aerosols (i.e., to remain present in the environment for a long time and being able to travel via ventilation systems) increase the ability of the virus to travel longer distances away from its source, thus exposing larger numbers of individuals to the virus [9].

The European Centre for Disease Prevention and Control (ECDC) reported that aerosol transmission is more probable in closed spaces in which many people stay for longer periods. It is also known to occur during aerosol-generating procedures, such as intubation [15]. Several recent studies suggest the plausibility of transmission of SARS-CoV-2 via aerosols [14, 16-18]. Setti et al. [17] suggested that confirmation of airborne transmission might explain the vast spread of the virus worldwide, which could hardly be ascribed only to human-to-human contact and fomite transmission. Shen et al. [18] reported that aerosol transmission is possible, especially if a person is exposed to high concentrations of aerosol for a long period in a relatively confined space. In a recent study, Zhang et al. [19] tried to evaluate the SARSCoV-2 infection risk via aerosol transmission in case of a south China seafood market. The study is based on currently available information pertaining to SARS-CoV-2 and other coronaviruses. However, due to the present uncertainties about the virus, they were unable to confirm aerosol transmission between customers at a seafood market.

\section{Foodborne transmission}

Foodborne transmission means catching a foodborne illness when consuming contaminated food or drinks [20]. Food could be contaminated directly, or through food packaging, by respiratory droplets, contact or another route when food goes through the 'farm-totable' lifecycle [21]. However, CoVs cannot multiply in food, as they need animal or human hosts to do so [13]. Han et al. [21] postulated that SARS-CoV-2 could be transmitted via food. In a review, they described how contaminated cold-storage food could present a risk of infection and transmission between different regions or countries. However, the transmission of SARS-CoV-2 via food or food packaging
The difference between droplets and aerosols is not only related to their size but also the distance they can travel, and the time they can remain in the air. Droplets usually spread and fall within a radius of $1-2 \mathrm{~m}$ from their source, all within seconds from the moment they originated. Aerosols, in contrast, can stay present in the environment for minutes or even hours while carrying their viral load and travel over a long distance.

Shen et al. reported that aerosol transmission is possible, especially if a person is exposed to high concentrations of aerosol for a long period in a relatively confined space.

\section{The transmission of} SARS-CoV-2 via food or food packaging was considered as highly unlikely. 
Viruses spread from faeces through three primary routes: 1) water, 2) surfaces, or 3 ) insects that scavenge on faeces. These insects become vectors. From these environments, viruses may reach the mouths infecting both respiratory and intestinal tracts of susceptible hosts.

The behaviour of a virus after being released from an infected individual can be affected by environmental factors, such as temperature, humidity, climate change, and air pollution. was considered as highly unlikely $[13,22]$. In a recent paper by Anelich et al. [22], it was reported that there is no evidence for SARS-CoV-2 having a negative impact on food safety. However, they highlighted an advantage of Food Safety Management System (FSMS), which also includes Good Hygiene Practices (GHP). It could be assumed that has been helping prevent the spread of SARS-CoV-2 along with other potential microbiological contamination. The GHP standard, among others, already includes handwashing with soap and water for at least $20 \mathrm{~s}$ at critical moments and sanitizing of hands when needed.

\section{Faecal-oral transmission}

Heller et al. [23] hypothesised about faecal-oral transmission as being a route of SARS-CoV-2 spread and transmission. Viruses spread from faeces through three primary routes: 1) water, 2) surfaces, or 3) insects that scavenge on faeces. These insects become vectors. From these environments, viruses may reach the mouths infecting both respiratory and intestinal tracts of susceptible hosts. However, it was highlighted that there is a lack of research regarding the faecal-oral transmission of SARS-CoV-2; consequently, the hypothesis could not be confirmed.

Thus far, human-to-human and fomite transmission have been confirmed. Also, there is a high possibility that aerosol transmission has been contributing to the exponential growth of cases. However, due to the lack of studies and the absence of substantiated proof, it would be highly premature to come to a conclusion about how each transmission route contributes to the increased risk of infection. The scarcity of information is also prevalent in the area of virus infectivity, either in aerosols or fomites [9].

Based on current information, we presume that foodborne and faecaloral transmission routes are very unlikely. Although aerosol transmission is probably more plausible, there are still no solid proofs. This situation could be possibly attributed to the great difficulty of detecting SARSCoV-2 in aerosols. Morawska and Cao [14] explained that sampling for the presence of the virus requires good knowledge of the airflow from an infected person, and this sampling should be given enough time to collect enough copies of the virus. Obviously, this makes sampling even more difficult.

\section{PRESENCE AND PERSISTENCE OF THE VIRUS IN THE ENVIRONMENT}

The transmission of viruses, including SARS-CoV-2, is attributed mainly to the virus' ability to survive when travelling from an infected individual to a susceptible host, which means that a virus must remain stable on different types of materials (such as fomites) or in the air (aerosols). The behaviour of a virus after being released from an infected individual can be affected by environmental factors, such as temperature, humidity, climate change, and air pollution [24]. 
van Doremalen et al. [25] evaluated the stability of SARS-CoV-2 on various surfaces. They confirmed that it was present on surfaces such as personal items, restrooms, room and floor surfaces and on materials such as plastic, stainless steel, copper, and cardboard. SARS-CoV-2 was found to be more stable on plastic and stainless steel than on copper and cardboard. It remained viable for $72 \mathrm{~h}$ (plastic), $48 \mathrm{~h}$ (stainless steel), $4 \mathrm{~h}$ (copper), and $24 \mathrm{~h}$ on cardboard after it was applied to the surface. The experiment was carried out at temperature ( $\mathrm{T}) 21^{\circ} \mathrm{C}$ to $23^{\circ} \mathrm{C}$ and relative humidity $(\mathrm{RH}) 40 \%$ while the titre was exponentially reduced. Another recent study detected SARS-CoV-2 on inanimate surfaces such as wood, ceramics, aluminium, glass, and waste containers and bags [26]. In both studies [25, 26], the virus persisted for days. In another experiment, a significant level of the infectious virus could still be found on the outer layer of a surgical mask seven days after the application of virus ( $\mathrm{T}: 22^{\circ} \mathrm{C}$ and $\left.\mathrm{RH}: 65 \%\right)$. In the same experiment, it was discovered that the virus is highly stable at room temperature and a wide range of $\mathrm{pH}(\mathrm{pH} 3-10)$ [27].

Thus far, only a few studies have confirmed the presence and persistence of SARS-CoV-2 in aerosols. An experiment performed by van Doremalen [25] confirmed that the virus remained viable in aerosols for the duration of the experiment $(3 \mathrm{~h}$ ), while the infectious titre was reduced from $10^{3,5}$ to $10^{2,7}$ per litre of air. The experiment was carried out at $\mathrm{T} 21-23^{\circ} \mathrm{C}$ and $65 \% \mathrm{RH}$. Similarly, in another experiment, by Fengs et al. [28], it was confirmed that SARS-CoV-2 could remain viable in aerosols for a relatively long time (up to $16 \mathrm{~h}$ ) under room-like conditions and potentially spread through aerosols. During an experiment in a hospital by Chia et al. [29], SARS-CoV-2 infectious particles, with radius sized 1-4 $\mu \mathrm{m}$ and larger than $4 \mu \mathrm{m}$, were detected inside an isolation room occupied by a COVID-19 patient. The contamination of surfaces was higher in the first week of disease and noticeably lower after a week passed. However, viral culture results could not prove the viability of the virus contaminating the air or surfaces. Lu et al. [30] investigated the aerodynamic nature of SARSCoV-2 in two Wuhan hospitals. Lower concentrations of the virus were detected in isolation rooms and ventilated patient's rooms, while concentrations were higher in toilet areas (used by the patients), staff rooms, and two areas of the hospitals that were often overcrowded.

Although foodborne transmission has not yet been confirmed for SARSCoV-2, Han et al. [21] reported that laboratory studies found evidence that the virus remained highly stable on meat, fish, and animal skin for the duration of studies (14-21 days) at low temperatures $\left(4^{\circ} \mathrm{C},-40^{\circ} \mathrm{C}\right.$, and $-80^{\circ} \mathrm{C}$ ). Another unconfirmed transmission route is faecal-oral. However, due to the recorded presence of the virus in faeces, some questions had to be raised. Wang et al. [31] confirmed viable SARSCoV-2 in faeces; in another study [32], a rectal swab tested positive despite a negative nasopharyngeal Polymerase Chain Reaction (PCR) test from the same patient.

The infectivity and stability of SARS-CoV-2 can be affected by temperature. It was confirmed that SARS-CoV-2 inactivation was
Thus far, only a few studies have confirmed the presence and persistence of SARS-CoV-2 in aerosols. An experiment performed by van Doremalen [25] confirmed that the virus remained viable in aerosols for the duration of the experiment ( $3 \mathrm{~h}$ ), while the infectious titre was reduced from $10^{3,5}$ to $10^{2,7}$ per litre of air. The experiment was carried out at $\mathrm{T} 21-23^{\circ} \mathrm{C}$ and $65 \% \mathrm{RH}$. 
The infectivity and stability of SARS-CoV-2 can be affected by temperature. It was confirmed that SARS-CoV-2 inactivation was boosted by increasing temperature. The half-life of the virus ranged from 6.3 to $18.6 \mathrm{~h}$ while the temperature was $24^{\circ} \mathrm{C}$; however, it was much lower with higher temperature. At $35^{\circ} \mathrm{C}$, the half-life was reduced to a range from 1.0 to $8.9 \mathrm{~h}$. boosted by increasing temperature. The half-life of the virus ranged from 6.3 to $18.6 \mathrm{~h}$ while the temperature was $24^{\circ} \mathrm{C}$; however, it was much lower with higher temperature. At $35^{\circ} \mathrm{C}$, the half-life was reduced to a range from 1.0 to $8.9 \mathrm{~h}$. The same pattern was observed with humidity. SARS-CoV-2 expeditiously lost its infectivity as the levels of humidity increased [33]. Chin et al. [27] ascertained that the stability of SARS-CoV-2 varies in response to the temperature. While the virus was highly stable at $4^{\circ} \mathrm{C}$, it was very sensitive to heat. Casanova et al. [34] assessed the effects of air temperature and relative humidity on CoV's survival. The persistence of these viruses was higher at $4^{\circ} \mathrm{C}(28$ days), and it was most difficult to inactivate at $20 \% \mathrm{RH}$. Inactivation was slow at $4^{\circ} \mathrm{C}$, faster at $20^{\circ} \mathrm{C}$ and the fastest at $40^{\circ} \mathrm{C}$. Also, low $\mathrm{RH}$ contributed to slower inactivation of the viruses.

SARS-CoV-2 could be present anywhere, spreading either by an infected individual shedding their respiratory secretions or through aerosols. Some materials might be a better habitat, thus the observed persistence of the virus. Such materials include metals (e.g., stainless steel), glass, and porous fabrics. In contrast, on surfaces like copper, latex, and less porous fabric, the virus showed less persistence [35]. SARS-CoV-2's stability is greatly impacted by temperature, relative humidity, and $\mathrm{pH}$ level. It tends to survive longer at low temperatures, low relative humidity, and within a wide range $\mathrm{pH}$ (from 3 to 10) [27, $33,34]$. In a recent research study, Biryukov et al. [33] developed a simple mathematical model to estimate the virus decay on nonporous surfaces under a range of conditions, which could help identify indoor environments with higher persistence of the virus. However, the infectively of the virus within the various aforementioned environmental factors is a crucial yet missing piece of information.

\section{PREVENTIVE AND CONTROL MEASURES OR NPIS}

In order to stop the spread of SARS-CoV-2, NPIs were implemented all over the world differing between the countries or even regions. The ECDC described NPIs as public health measures for preventing and/or controlling the transmission of SARS-CoV-2 in the community [15]. For as long as there is no vaccine available for the virus, NPIs are considered to be the most effective public health intervention against COVID-19. According to the ECDC, NPIs are organized in three main categories 1) individual (hand hygiene, respiratory hygiene, and use of protective masks), 2) environmental (cleaning, disinfection, and adequate ventilation), and 3) population-related NPIs (raising awareness of physical distance, limiting or restricting movement and gathering of people) [15] (Table 1). Cheng et al. [36] reported that most widely used NPIs in the current pandemic have been travel restrictions, border closings, school and business closing, massive PCR testing, quarantining, (self)isolating, contact tracking, community-wide mask use, hand washing and disinfection, physical distancing and curfews. Below, we describe the five main NPIs: ventilation, cleaning and disinfection, hand hygiene, physical distancing, and protective masks. 
Table 1. Transmission routes and recommended Non-Pharmaceutical Interventions for their prevention

\begin{tabular}{|l|l|}
\hline \multicolumn{1}{|c|}{ TRANSMISSION ROUTE } & \multicolumn{1}{c|}{ NPIs } \\
\hline Direct contact (human-to-human) & - Use protective face mask \\
& - Hand hygiene \\
& - Respiratory hygiene \\
& - Physical distancing \\
\hline Indirect contact (with fomites) & - Hand hygiene \\
& - Cleaning and disinfecting of objects and surfaces \\
\hline Airborne* & - Use protective face mask** \\
& - Adequate ventilation of indoor places \\
\hline Foodborne*** & - Hand hygiene \\
& - Respiratory hygiene \\
& - Cleaning and disinfecting of objects and surfaces \\
\hline
\end{tabular}

NPI - Non-Pharmaceutical Intervention; *very possible transmission route with no solid proof but NPIs are still recommended; **not every kind of protective mask can prevent this transmission route; ${ }^{* *}$ currently no proof for this kind of transmission but NPIs are still recommended.

\section{Ventilation}

The ECDC claims that heating, ventilation, and air-conditioning have been playing important roles in reducing the spread of SARS-CoV-2 in indoor spaces, which implies that an increased rate of air exchange, a decrease in recirculation of air and an increase in the use of outdoor air (i.e., natural ventilation) can contribute to reducing the spread of the virus [15]. Several recent studies' findings have confirmed this claim [14-16, 18, 37, 38]. Morawska and Cao [14] emphasised the significance of adequate ventilation for indoor spaces because it can significantly deter the spread of SARS-CoV-2 via air. As discussed earlier in this article, airborne particles can be carriers of the virus; therefore, if found within indoor spaces, they should be removed. Adequate ventilation can help with this removal. Additionally, they suggested avoiding staying in another person's airflow and to minimize the number of people sharing the same space. Amoatey et al. [37] added that implementing personalized ventilation and personalized exhaust systems (PV-PE) within microenvironments, where possible, should be considered. They also pointed out that natural ventilation could be impractical in some areas with high annual temperatures. For example, the Middle East has high annual average temperatures and their modern buildings' architecture, in general, only allows mechanical ventilation. Such circumstances diminish the possibility of using natural ventilation.

Dai and Zhao [38] investigated the influence of ventilation rate on infection possibility within indoor places. The study supports that when an infector remains in an indoor space for a longer time, the infection risk becomes relatively higher (infection probability is approximately $2 \%$ at the ventilation rate of $500-2500 \mathrm{~m}^{3} / \mathrm{h}$ per infector for 15 min of exposure). They highlighted the significance of a sufficient ventilation rate for offices, classrooms, public transport, and other confined spaces in reducing infection's possibility. Furthermore, Shen et al. [18]
The ECDC claims that heating, ventilation, and air-conditioning have been playing important roles in reducing the spread of SARS-CoV-2 in indoor spaces, which implies that an increased rate of air exchange, a decrease in recirculation of air and an increase in the use of outdoor air (i.e., natural ventilation) can contribute to reducing the spread of the virus.

When an infector remains in an indoor space for a longer time, the infection risk becomes relatively higher (infection probability is approximately $2 \%$ at the ventilation rate of $500-2500 \mathrm{~m}^{3} / \mathrm{h}$ per infector for 15 min of exposure). 
Many studies have illustrated the importance of adequate ventilation in curbing the transmission of SARS-CoV-2.

These findings highlighted

1) the importance of adequate ventilation in indoor spaces (increased rate of air exchange, decrease in recirculation of air),

2) the importance of natural ventilation, and 3) the need to limit the number of people allowed indoor at the same time.

Based on the thus-far known information about SARSCoV-2 transmission routes and its presence and persistence in the environment, cleaning and disinfecting play an essential role in reducing its spread. conducted research focusing on ventilation in public transport, which includes aeroplanes, high-speed rail, subways, buses, taxis, ferries, and others in China. They reported that adequate ventilation could efficiently reduce the concentration of suspended matters in confined spaces, which can lead to reductions in the transmission of pathogen droplets. Also, air-conditioning filters must be cleaned or replaced frequently. In a literature review from Chirico et al. [39] air-conditioning systems were discussed as possibly contributing to the spread of SARS-CoV-2. However, there is no strong evidence to prove this. Based on the recent outbreaks reported during a choir practice session, in a call centre, and gym classes, they suggested that a situation with inadequate ventilation in conjunction with droplet transmission and crowded indoor places can increase the risk of infection.

To summarise, many studies have illustrated the importance of adequate ventilation in curbing the transmission of SARS-CoV-2. These findings highlighted 1) the importance of adequate ventilation in indoor spaces (increased rate of air exchange, decrease in recirculation of air), 2) the importance of natural ventilation, and 3 ) the need to limit the number of people allowed indoor at the same time. However, to date, there is no information about the amount of viral emission in indoor places. Buonanno et al. [16] attempted to estimate the amount of airborne viral emission and strived to fill the knowledge gap by trying to evaluate the viral load emitted by infected individuals. Such information is crucial for engineers and indoor air quality experts for simulating the spread of SARS-CoV-2 through indoor spaces.

\section{Cleaning and disinfection}

Based on the thus-far known information about SARS-CoV-2 transmission routes and its presence and persistence in the environment, cleaning and disinfecting play an essential role in reducing its spread. The ECDC reported that SARS-CoV-2 is an enveloped virus; consequently, it is sensitive to common detergents and disinfectants. Also, the ECDC conveyed the importance of frequent cleaning, especially for often-touched surfaces, such as door handles, bannister rails, buttons, buses, and similar [15].

Castaño et al. [9] reported that cleaning and disinfection are needed to inactivate and remove the virus from surfaces. To inactivate a virus, its ability to be infective (fusing with a host cell, intact envelope, and nucleocapsids) must be destroyed. They also described the currently used disinfecting strategies for inactivating SARS-CoV-2, including ultraviolet (UV) and solar irradiation, chemical disinfection, plasma disinfection, heat treatment, self-disinfecting materials/surfaces, and hand hygiene. DeLeo et al. [40] discussed the group of disinfectants called Quaternary Ammonium Compounds (QACs), for SARS-CoV-2 inactivation on surfaces and found them to be efficient at doing so. They also emphasized the necessity of disinfecting indoor air frequently because of the virus' ability to survive in aerosol for a prolonged period. To control the spread of this virus, they suggest the development of specific 
environmental disinfection protocols. The ECDC [41] prepared guidance for environmental cleaning of non-healthcare facilities exposed to SARSCoV-2. When a person infected with the virus uses public facilities such as public offices/transport, schools, and similar, they might contaminate the air and surfaces, consequently increasing the risk of infection amongst facilities' users. In this above-mentioned guidance, the ECDC recommends cleaning potentially contaminated premises before they are re-used. For cleaning, warm water and household detergents should be used. Disinfection should be performed with common disinfectants, such as $70 \%$ ethanol. A person who is cleaning or disinfecting surfaces should wear disposable personal protective equipment (PPE), such as gloves, goggles, gowns, and masks. PPE should be disposed of after cleaning and treated as infectious material.

We should be aware that SARS-CoV-2 can also be disruptive to the food industry. In a review, Dev Kumar et al. [42] discussed the importance of biocides used to control the spread of SARS-CoV-2 in the food industry, where frequent cleaning and disinfecting are essential. For sufficient surface disinfection against SARS-CoV-2, they suggested ethanol (70\% or more), povidone, iodine, hypochlorite, and QACs combined with alcohol. To prevent the presence of viral load in aerosols, they suggested using hydrogen peroxide vapour, chlorine dioxide, ozone, and UV light. They also emphasised that cleaning and disinfecting must be employed collectively with other NPIs.

However, in the matter of food production and processing, the Food and Agriculture Organization (FAO) and the WHO [43] warned about risks of using chlorine-based disinfectants, as they can increase exposure to chemical residues, which could cause health problems. Furthermore, in this mass use of disinfectants, the ECDC advised caution when spraying disinfectants (also known as fumigation) or using UV light irradiation. They considered these two practices to be unsafe for outdoors or large indoor spaces (e.g., a classroom). The ECDC based this view on the lack of effectiveness and possible harm to the environment and people due to exposure to irritant chemicals [15]. Furthermore, particular attention should be given to the cleaning and disinfecting of households and to the preparing, storing, and discharging of cleaners and disinfectants. Gharpure et al. [44] found that $30 \%$ of the surveyed people were using non-recommended high-risk practices with the intent of preventing the transmission of SARS-CoV-2. Examples of these practices include using bleach on food products, applying household cleaning and disinfectant to the skin, and inhaling or ingesting cleaning and disinfecting products. They also found that there were significantly more calls to poison centres related to cleaning and disinfection misuse since the outbreak of the pandemic. They asserted that public messaging should be used to communicate and encourage evidence-based and safe cleaning and disinfecting practices to stop the spread of the virus in households.

Although cleaning and disinfecting are crucial in controlling the spread of SARS-CoV-2, Singh [45] warned about accelerated antimicrobial resistance during this pandemic. The reason for it is in over-use of
For cleaning, warm water and household detergents should be used. Disinfection should be performed with common disinfectants, such as $70 \%$ ethanol.

To prevent the presence of viral load in aerosols, they suggested using hydrogen peroxide vapour, chlorine dioxide, ozone, and UV light. 
The recommended duration of hand washing is 20 to 40

seconds. If the hands are possibly contaminated, hand disinfectant should be used after washing.

In its Guidelines for Hand Hygiene in Health Care the WHO recommends using two alcohol-based formulations (75-85\% ethanol and isopropanol) for hand disinfection to inactivate and reduce the spread of pathogens. These two are fast-acting and have a broadspectrum of biocidal activity. Importantly, they are easily accessible and safe. antibiotics and many different cleaning and disinfecting products. Overuse causes problems such as alcohol-disinfectant resistance of Enterococcus faecium, which can cause a variety of infections in humans. Furthermore, the strengthening microbial resistance that has been observed that far could cause great harm to human health. Ejtahed et al. [46] expressed concern about the mass daily use of detergents and household cleaning products due to the pandemic. They summarised that some of these cleaning products contain chemicals that are linked to gut dysbiosis, which plays an important role in humans' immune system.

Furthermore, Getahun et al. [47] reported the wide use of environmental and personal disinfectants in both healthcare and non-healthcare settings. This wide use of disinfectants can increase a cross-resistance to some antibiotics for drug-resistant strains. DeLeo et al. [40] warned that QACs negatively impact the environment. As they are usually disposed of 'down the drain', they end up in wastewater treatment systems. From there, QACs can penetrate aquatic environments and present a potential risk for aquatic organisms.

Regardless of how serious microbial resistance increase, gut dysbiosis, and environmental damage are, we should continue with frequent cleaning and disinfection. Alternatively, if we do not, the spread of SARS-CoV-2 could worsen. It is necessary to explain that microbial resistance can be lowered again, especially with more control over antibiotics. Particular attention should be given to the use of cleaning and disinfecting products in households. A multimedia campaign could be useful for demonstrating appropriate uses and highlighting the consequences of any misuse. To lower the negative impacts of QACs on the environment, some remediating technologies should be developed. Until then, the presence of QACs should be monitored [48].

\section{Hand hygiene}

The ECDC described hand washing as the frequent and efficient washing of hands with soap and water. It can also refer to the cleaning of hands with solutions, gels, or tissues. The recommended duration of hand washing is 20 to 40 seconds. If the hands are possibly contaminated, hand disinfectant should be used after washing. This NPI is recommended in both healthcare and community settings in order to contribute to reducing the spread of SARS-CoV-2 [15]. In its Guidelines for Hand Hygiene in Health Care the WHO recommends using two alcohol-based formulations (75-85\% ethanol and isopropanol) for hand disinfection to inactivate and reduce the spread of pathogens. These two are fast-acting and have a broad-spectrum of biocidal activity. Importantly, they are easily accessible and safe. The WHO has extended this recommendation's applicability to include SARS-CoV-2. This recommendation was based on the efficiency of these two alcohol-based formulations in inactivating other CoVs and MERS [49]. In an experiment performed by Kratzel et al. [50], both alcohol-based disinfectants recommended by the WHO were tested. The two were found sufficient in inactivating SARS-CoV-2 within 
$30 \mathrm{~s}$ at tested concentrations of $85 \%$ (ethanol) and $75 \%$ (isopropanol). However, ethanol and isopropanol are mostly effective against enveloped viruses and Gram-positive/negative bacteria rather than non-enveloped viruses and bacterial spores [51].

Castaño et al. [9] explained that hand hygiene is essential for reducing virus transfer from fomites to facial membranes (mouth, nose, eyes). On average, adults touch their face 23 times per hour, which means the risk of becoming infected via contaminated hands is relatively high. It is important that hand washing is frequent and efficient. In addition to hand washing, hand disinfectants, such as alcohol and isopropanol-based antiseptics, can be used. Hand disinfectants are also an alternative when hand washing is not possible. Using $75 \%$ alcohol hand disinfectant gel or wipes should reduce the possibility of infection caused by hand-to-mouth, hand-to-nose, or hand-to-eye contact. Hands should be disinfected every time a person has touched a potentially contaminated object or surface [52].

In healthcare facilities, Health Care Workers (HCWs) should follow the 'five moments for hand hygiene' recommended by the WHO [53]. This approach defines the main moments when HCWs should clean their hands. These moments are 1) before touching a patient, 2) before clean/aseptic procedures, 3) after body fluid exposure/risk, 4) after touching a patient, and 5) after touching patient's surroundings [53].

However, frequent handwashing can have some negative consequences. Cavanagh and Wambier [54] draw attention to rational hand hygiene during the pandemic. Recurring hand washing can lead to skin damage, which creates a new route of entry for SARS-CoV-2. Especially exposed to this are HCWs, who may perform handwashing with water and soap more than 10 times per day. To reduce the risk of damaged hand skin (also called hand eczema), using gloves, hand cream or moisturizers, and ethanol-based disinfectants is recommended (instead of handwashing when only the decontamination of hands is needed). Regularly applying hand creams and moisturizers prior to handwashing can help reduce the chances of skin damage.

\section{Physical distance}

Based on the ECDC guidelines, physical distancing includes 1) keeping a recommended 1-2 $\mathrm{m}$ distance between individuals 2 ) closing of public spaces (non-essential shops, restaurants, bars, and entertainment settings), 3) closing public transport, 4) closing workplaces, 5) encouraging work from home, 6) closing schools (kindergartens, primary schools, high schools, and universities), 7) protecting high-risk groups and vulnerable populations, and 8) stay-at-home orders and recommendations [15]. Another three NPIs that include physical distance are isolation, quarantine, and movement restrictions (international or domestic movement). The ECDC reported that isolation of confirmed or very plausible cases of COVID-19 is an efficient NPI, which is meant for patients who do not require hospitalization. Isolation of patients can be either nonmandatory or mandatory, depending on national regulations.
On average, adults touch their face 23 times per hour, which means the risk of becoming infected via contaminated hands is relatively high. It is important that hand washing is frequent and efficient.

Using $75 \%$ alcohol hand disinfectant gel or wipes should reduce the possibility of infection caused by handto-mouth, hand-to-nose, or hand-to-eye contact. Hands should be disinfected every time a person has touched a potentially contaminated object or surface.

To reduce the risk of damaged hand skin (also called hand eczema), using gloves, hand cream or moisturizers, and ethanolbased disinfectants is recommended (instead of handwashing when only the decontamination of hands is needed). 
Physical distancing includes

1) keeping a recommended 1-2 $\mathrm{m}$ distance between individuals 2) closing of public spaces (non-essential shops, restaurants, bars, and entertainment settings),

3) closing public transport, 4) closing workplaces,

5) encouraging work from home, 6) closing schools

(kindergartens, primary schools, high schools, and universities), 7) protecting

high-risk groups and vulnerable populations, and 8) stay-at-home orders and recommendations.
This measure aims to reduce the possibility of someone that is probably infected to transmit the virus further. A person could presume that they are infected based on the existence of symptoms such as fever, cough, myalgia, fatigue, loss of senses of smell and taste, nausea, vomiting, diarrhoea, and other less-common symptoms. However, not developing any symptom should not permit someone not to perform or finish their isolation.

Another recommended measure is quarantine implementation. Quarantine is an isolation option considered for healthy individuals who have had a high-risk exposure to COVID-19 positive patient. In some countries, quarantine is also obligatory for individuals who could be exposed to situations with high-risk of SARS-CoV-2 transmission. For example, travellers from areas with high daily numbers of new infections and family members of confirmed infected individuals are quarantined. Just like isolation, quarantine could be either mandatory or nonmandatory based on national regulations. The ECDC mentions that the duration of quarantines can differ from country to country and often lasts from 1-14 days. This measure is the most effective if implemented early and along with other NPIs [15]. Koo et al. [55] investigated different possible actions taken to reduce virus spread between individuals at schools, workplaces and at homes. They concluded that the quarantine of infected individuals and their family members, school closure, and workplace physical distancing are the most effective actions for the reduction of virus spread.

Avoiding physical contact and maintaining physical distance is considered to be the main preventive measure in this ongoing pandemic [15]. Many governments described the physical distance that needs to be maintained is at least 1.5 or $2 \mathrm{~m}$, based on recommendations by WHO [10]. The ECDC [15] recommends implementing posters, floor markings, seat markings or rearrangement to remind people to practice physical distancing. In places that tend to become crowded, such as shops, restaurants and public transport, this kind of re-organization is necessary.

Keeping a recommended physical distance seems doable in theory, but when it comes to some places, such as nursing homes, households, and refugee camps, physical distancing may be difficult or even impossible. Subbaraman [56] reported on five Aegean islands, which are located to the east of Greece, which have capacities for approximately 6,000 people, yet about 40,000 refugees are waiting to receive their asylum status. Their living conditions are poor, with no access to running water or toilets. Their temporary homes are either tents or cardboard boxes, and these areas are overcrowded. In such a situation, physical distancing, quarantine, or isolation measures cannot be applied.

In another study, Wang et al. [57] underscored the importance of practising NPIs in nursing homes, orphanages, and prisons. Such facilities are very likely to have relatively confined environments. The residents of nursing homes, orphanages, and prisons can have limited mobility or deprived freedom. Usually, they live in circumstances in 
which close contact is unavoidable, which means the risk for SARSCoV-2 spread is high. Kirbiyik et al. [58] reported about a recent COVID-19 outbreak in an American jail. They were the first to use network analyses and visualization techniques to describe a viral outbreak in a jail. The study included 5,884 infected persons of which $3,843(65 \%)$ were detained persons and 2,041 (35\%) were staff members between $1^{\text {st }}$ of March and $30^{\text {th }}$ of April. NPIs were applied during this outbreak, such as limited visiting, suspension of some activities (e.g., contact sports), conversion of cells to single occupancy and use of protective masks for both detained persons and staff members. The study covered only virus transmission via human-tohuman contact and did not include the possible spread of SARS-CoV-2 outside the jail. Staff members contributed to the spread more than detained persons did, probably due to their frequent movement. They outlined potential high risk transmission points for staff members, including staff meetings and breakrooms. These 'high-risk transmission points' should be given more attention in order to reduce SARS-CoV-2's ability to spread.

Households are considered as another case in which physical distancing is difficult. Wang et al. [59] studied the decreased secondary transmission of SARS-CoV-2 in households using facemasks, disinfecting, and physical distancing. They claim that transmission of a virus within families and close contacts is the reason for most of the epidemic growth. The research confirmed that mask use by both infected individuals and family members reduced the transmission of the virus. However, they noted that disinfecting hands with chlorine or ethanolbased disinfectants and physical distancing (as much as it is possible) contributed to additional reductions of transmission. They stated that NPIs should be used not only in public places but also in households.

As mentioned, movement restriction is another part of physical distancing that was applied during this pandemic. Murphy et al. [60] reported that air travel has the potential to increase the spread of SARS-CoV-2. In their study, they discussed a national outbreak of COVID-19 linked to air travel in summer of 2020. The duration of the flight was $7 \mathrm{~h}$; it had $17 \%$ occupancy. The outbreak involved 59 SARSCoV-2 cases, of which 13 cases originated from the flight, and the remaining 46 were infected via the original 13 cases. The outbreak happened even though travellers wore masks and were supposed to maintain physical distance. Flight cases could become infected in-flight, during overnight transfer or unknown acquisition before the flight. They summarised that using NPIs, prohibiting travel for symptomatic persons, restricting movement on arrival and contact tracing should be a necessity if air travel is operating.

Physical distancing should be practised along with other NPIs. Setti et al. [17] reported that keeping the recommended 1.5 to $2 \mathrm{~m}$ distance is only effective when protective masks are used by both infected individuals and people who could become infected. However, in the above-described facilities where physical distancing is not always possible, the use of other NPIs should be increased, for example, constant mask-wearing,
Avoiding physical contact and maintaining physical distance is considered to be the main preventive measure in this ongoing pandemic.

Many governments described the physical distance that needs to be maintained is at least 1.5 or $2 \mathrm{~m}$, based on recommendations by $\mathrm{WHO}$. 
They reported that in a 14-day period of physical distancing, the number of social-media-posts talking about anxiety and depression escalated, while positive-orientated posts diminished.

A medical mask is a device covering the mouth, nose, and chin to provide a barrier that limits the transmission of pathogens between medical staff and patients. These masks have to be standardized, unlike nonmedical masks (also called community masks).

There are homemade and commercial masks, which can be made of cloth or other materials, including paper.

These masks are not standardized and are not intended for use in healthcare settings. more frequent cleaning and disinfection, adequate ventilation, and contact tracing.

Most physical distancing NPIs have a high impact in preventing the spread of SARS-CoV-2. However, the societal impact can differ between NPIs. The societal impact of keeping a distance of 1-2 $\mathrm{m}$ and working from home is low. Greater societal impact is expected from measures such as the closing of public spaces, the closing of workplaces and protecting high-risk and vulnerable populations. The highest societal impact is expected from measures, including the closing of public transport, the closing of schools, and stay-at-home orders [15]. Vieira et al. [61] discussed some side effect of physical distancing (i.e., full lockdown, quarantining, isolation, stay-at-home orders) that could have a significant impact on people's lives. They reported that in a 14-day period of physical distancing, the number of social-media-posts talking about anxiety and depression escalated, while positive-orientated posts diminished. Another negative aspect that has been happening is misinformation, which in combination with physical distancing can lead to insecurity, anxiety, fear, emotional tension, and a false sense of security. All together, these jeopardise the quality of life.

\section{Protective masks}

When SARS-CoV-2 started spreading worldwide, the WHO and the ECDC recommended that protective masks should be reserved for people with symptoms and HCWs [36]. Later, on the $6^{\text {th }}$ of April, the WHO issued a temporary guideline recommending the use of masks; however, it was not mentioned that community-wide mask-wearing could prevent the transmission of the new virus [62]. On the $8^{\text {th }}$ of April, the ECDC issued a technical report saying that community-wide maskwearing should be considered, especially, in busy indoor places, despite the absence of any proof of this measure efficiency [63]. However, to date, several papers have addressed the importance of mask use [36, 64-66]. MacIntyre and Chughtai [67] reported that masks and respirators are generally used for protection against respiratory infections. Furthermore, they explained that masks are essential for respiratory diseases, especially when no medications or vaccines are available, and transmission routes are uncertain.

Based on the ECDC [15] guidelines, two kinds of protective masks are distinct and need to be differentiated. First, a medical mask is a device covering the mouth, nose, and chin to provide a barrier that limits the transmission of pathogens between medical staff and patients. These masks have to be standardized, unlike non-medical masks (also called community masks). The latter exists in various forms and can be made from different materials. For example, there are homemade and commercial masks, which can be made of cloth or other materials, including paper. These masks are not standardized and are not intended for use in healthcare settings.

The pandemic of SARS-CoV-2 triggered a PPE crisis around the world; part of this crisis has been the shortage of protective masks. Therefore, 
the public has had to start using cloth masks. In a review, Beesoon et al. [68] highlighted the concerns around reliability of cloth masks. There is also a concern about so-called 'Do It Yourself' (DIY) trend, in which people make masks on their own using all kinds of materials without knowing their filtration abilities. However, Konda et al. [69] measured the filtration efficiencies of commonly available fabrics, such as cotton, silk, flannel, various synthetics and their amalgamation that could prevent aerosol transmission (particle sizes range $\sim 10 \mathrm{~nm}$ to $6 \mu \mathrm{m}$ ) of SARSCoV-2. The experiment results revealed that cotton, natural silk, and chiffon provide acceptable protection with filtering about $50 \%$ of particles in the entire tested size range. Materials such as silk and chiffon found to be effective in combination with other materials such as cotton. The most effective filtration was recorded when multiple layers of different fabric were combined. The hybrid of cotton and silk/chiffon/flannel increased the efficiency of filtration to more than $80 \%$. This effect might be due to a combined effect of mechanical and electrostatic-based filtration, which these materials provide. A significant decline in filtration was observed when masks were not properly fitted to individuals' faces, and there was a gap between the mask and face.

Similarly, the efficacy of cloth masks was measured by the Jožef Stefan Institute; 150 different cloth masks were tested. The results showed filtration efficacy between $19 \%$ and $82 \%$. Better filtration was provided by cotton masks that were creased instead of smooth. Also, fabric with high thread-count or consisting of some polymer materials was more efficient in filtration in contrast to low thread-count and non-polymer materials. Tested surgical masks had efficiencies of $77 \%$ to $81 \%$, while the materials used for their production had efficiencies of $91 \%$ to $99.5 \%$ [70].

Lustig et al. [71] evaluated the effectiveness of common fabrics for blocking aerosols of SARS-CoV-2-like nanoparticles. In their experiment, they included over 70 different fabrics that can be used as a cloth mask. The materials found to provide the most efficient filtration were terry cloth, flannel, and quilting cotton. Also, filtration levels increased with additional barrier layers of nonwoven polypropylene, polyester, and polyaramid.

Beesoon et al. [68] pointed out the problem of a false sense of protection amongst people while wearing masks. This sense could be especially problematic if individuals then start to engage in other risky behaviours, such as not keeping physical distance or not practising hand hygiene. Similarly, Matuschek et al. [64] reported that protective masks are suitable to prevent transmissions by droplets and are only effective when used properly combined with physical distancing of at least $1.5 \mathrm{~m}$. Also, they discussed both possible shortcomings and advantages of protective masks. As shortcomings, they listed mask shortage, a false sense of security, inappropriate mask use, mask dampness, and no regular mask swapping. However, the advantages of masks are in reducing the spread of SARS-CoV-2 and reducing the possibility to being infected with it.
The experiment results revealed that cotton, natural silk, and chiffon provide acceptable protection with filtering about $50 \%$ of particles in the entire tested size range. Materials such as silk and chiffon found to be effective in combination with other materials such as cotton. The most effective filtration was recorded when multiple layers of different fabric were combined.

Tested surgical masks had efficiencies of $77 \%$ to $81 \%$, while the materials used for their production had efficiencies of $91 \%$ to $99.5 \%$.

The advantages of masks are in reducing the spread of SARS-CoV-2 and reducing the possibility to being infected with it. 
On the first bus, he did not wear a mask, and he transmitted SARS-CoV-2 to 5 people on the bus. On the second bus, he wore a mask, and he did not infect anyone on that bus.

Abbasi et al. warned about the possibility of a surge of microplastic pollution in global ecosystems, as a consequence of mass mask use during this pandemic. Microplastics in marine ecosystems can contribute to colonization of pathogenic microorganisms.
In another study, Desai and Aronoff [72] explained that in the case of SARS-CoV-2, infected individuals can spread the virus even when they do not show any symptoms. In this case, cloth masks can at least limit the spread of the virus from infected persons to others. However, cloth masks may not be so successful in preventing the infection for the person wearing them, especially if the emission of a viral load is high.

An event in which masks possibly reduced the spread of SARS-CoV-2, was described by Liu and Zhang [73]. In a typical case of cluster outbreak in public transportation in China, a patient travelled from Chongqing and transferred buses once. On the first bus, he did not wear a mask, and he transmitted SARS-CoV-2 to 5 people on the bus. On the second bus, he wore a mask, and he did not infect anyone on that bus. Furthermore, in an experiment performed in 15 American states between the $8^{\text {th }}$ of April and the $15^{\text {th }}$ of May 2020, Wel Lyu and Wehby [66] assessed community-wide use of facemask. They confirmed that mandating the use of masks in public has a role in reducing the spread of SARS-CoV-2. However, these effects were observed while masks used alongside other NPIs, such as physical distancing. Cheng et al. [36] also explored the role of community-wide masks wearing in tackling the SARS-CoV-2 pandemic. In their study, they focused on Honk Kong Special Administrative Region (HKSAR) within the first 100 days of the epidemic $\left(31^{\text {st }}\right.$ of December to $8^{\text {th }}$ of April). In that region, community-wide mask-wearing was practised in an early stage of local epidemic notwithstanding the WHO and ECDC recommendations that masks should be reserved for HCWs. More cases were reported during off-mask activities than on-mask. They concluded that incidences of COVID-19 in HSKAR (community-wide mask-wearing) in the first 100 days of the epidemic was remarkably lower compared to non-mask-wearing countries, such as Spain, Italy, Germany, France, the USA, the UK, Singapore, and South Korea. Compared to HKSAR, these countries had similar population density, healthcare system or physical distancing measures.

To summarise, wide-community mask use tends to contribute to reducing the spread of SARS-CoV-2. It has been widely recommended and, in some countries, mandatory, especially within indoor public spaces. However, masks become waste containing microplastic. Abbasi et al. [74] warned about the possibility of a surge of microplastic pollution in global ecosystems, as a consequence of mass mask use during this pandemic. Microplastics in marine ecosystems can contribute to colonization of pathogenic microorganisms. Once these microorganisms become attached to microplastic, they can be transmitted to live organisms and cause diseases. Also, in the food industry, face mask use could present an additional health risk. When workers in the food industry wear masks and then touch them, while readjusting them, for example, they could contaminate their hands with Staphylococcus aureus bacteria. These bacteria can be found inside some people's noses and mouths. When a worker in the food industry has contaminated hands and then touches food, it can lead to food poisoning [75]. 


\section{CONCLUSION}

There is no doubt that the implemented and worldwide used NPIs can have also negative impacts on individuals, families, food safety, and the environment. However, there is a high possibility that following these NPIs will save lives by preventing the spread of SARS-CoV-2. NPIs' potential negative impact might still be less than the negative impact of an unchallenged pandemic. In order to control this pandemic, we should emphasise the importance of using a combination of NPIs collectively, as one NPI by itself does not sufficiently reduce transmissibility. In the future, once a vaccine is developed and used, most currently implemented NPIs will be cancelled. After this pandemic, however, good hand hygiene, respiratory hygiene and cleaning of surfaces should still be practised, as they can prevent other health-threatening pathogens. We should also be aware that some presently implemented NPIs can cause problems in the future. This includes microplastics in the environment as a consequence of mass mask use, microbial resistance as a consequence of frequent disinfecting, aquatic organisms' problems as a consequence of overusing QACs, and gut dysbiosis as a consequence of detergent use. We should address these problems now as early as possible.

\section{Acknowledgments}

The authors acknowledge the financial support from Slovenian Research Agency (research core funding No. P3-0388). The authors would also like to express their gratitude to Terry Jackson for language corrections.

\section{REFERENCES}

[1] Archived: WHO Timeline - COVID-19 [Internet]. Who.int. 2020 [cited 20 October 2020]. Available from: https://www.who.int/news/item/27-042020-who-timeline---covid-19.

[2] Apolone G, Montomoli E, Manenti A, Boeri M, Sabia F, Hyseni I, et al. Unexpected detection of SARS-CoV-2 antibodies in the prepandemic period in Italy. Tumori. 2020:300891620974755.

[3] Naming the coronavirus disease (COVID-19) and the virus that causes it [Internet]. Who.int. 2020 [cited 23 October 2020]. Available from: https://www.who.int/emergencies/diseases/novel-coronavirus-2019/ technical-guidance/naming-the-coronavirus-disease-(covid-2019)-andthe-virus-that-causes-it

[4] Coronavirus Update (Live): 57,001,890 Cases and 1,361,707 Deaths from COVID-19 Virus Pandemic - Worldometer [Internet]. Worldometers. info. 2020 [cited 20 October 2020]. Available from: https://www. worldometers.info/coronavirus/?utm_campaign=homeAdvegas1?

[5] Q \& A on COVID-19: Basic facts [Internet]. European Centre for Disease Prevention and Control. 2020 [cited 4 November 2020]. Available from: https://www.ecdc.europa.eu/en/covid-19/facts/questions-answers-basicfacts

[6] Middle East respiratory syndrome coronavirus (MERS-CoV) [Internet]. Who.int. 2020 [cited 4 November 2020]. Available from: https://www. who.int/health-topics/middle-east-respiratory-syndrome-coronavirusmers \#tab=tab_1

[7] FEM Wiki [Internet]. 2020 [cited 5 November 2020]. Available from: https://wiki.ecdc.europa.eu/fem/Pages/Transmission\%20routes.aspx
After this pandemic, however, good hand hygiene, respiratory hygiene and cleaning of surfaces should still be practised, as they can prevent other health-threatening pathogens. 
[8] He X, Lau EHY, Wu P, Deng X, Wang J, Hao X, et al. Temporal dynamics in viral shedding and transmissibility of COVID-19. Nature Medicine. 2020;26(5):672-5.

[9] Castano N, Cordts S, Jalil M, Zhang K, Koppaka S, Bick A, et al. Fomite transmission and disinfection strategies for SARS-CoV-2 and related viruses2020.

[10] WHO. Transmission of SARS-CoV-2: implications for infection prevention precautions [Internet]. Who.int. 2020 [cited 23 October 2020]. Available from: https://www.who.int/news-room/commentaries/detail/ transmission-of-sars-cov-2-implications-for-infection-preventionprecautions

[11] Li Q, Guan X, Wu P, Wang X, Zhou L, Tong Y, et al. Early Transmission Dynamics in Wuhan, China, of Novel Coronavirus-Infected Pneumonia. New England Journal of Medicine. 2020;382(13):1199-207.

[12] Basu S. Computational characterization of inhaled droplet transport in the upper airway leading to SARS-CoV-2 infection. medRxiv. 2020:2020.07.27.20162362.

[13] WHO, FAO. COVID-19 and food safety: guidance for food businesses: interim guidance, 07 April 2020. Geneva: World Health Organization; 2020 2020. Contract No.: WHO/2019-nCoV/Food_Safety/2020.1.

[14] Morawska L, Cao J. Airborne transmission of SARS-CoV-2: The world should face the reality. Environment International. 2020;139.

[15] Guidelines for the implementation of non-pharmaceutical interventions against COVID-19 In the EU/EEA and the UK. 2020.

[16] Buonanno G, Stabile L, Morawska L. Estimation of airborne viral emission: Quanta emission rate of SARS-CoV-2 for infection risk assessment. Environment International. 2020;141.

[17] Setti L, Passarini F, De Gennaro G, Barbieri P, Perrone MG, Borelli M, et al. Airborne transmission route of covid-19: Why 2 meters $/ 6$ feet of inter-personal distance could not be enough. International Journal of Environmental Research and Public Health. 2020;17(8).

[18] Shen J, Duan H, Zhang B, Wang J, Ji JS, Pan L, et al. Prevention and control of COVID-19 in public transportation: Experience from China. Environmental Pollution. 2020;266.

[19] Zhang X, Ji Z, Yue Y, Liu H, Wang J. Infection Risk Assessment of COVID-19 through Aerosol Transmission: a Case Study of South China Seafood Market. Environmental Science and Technology. 2020.

[20] WHO. Foodborne diseases [Internet] [cited 5 November 2020]. Available from: https://www.who.int/health-topics/foodborne-diseases\#tab=tab_1

[21] Han J, Zhang X, He S, Jia P. Can the coronavirus disease be transmitted from food? A review of evidence, risks, policies and knowledge gaps. Environmental Chemistry Letters. 2020.

[22] Anelich LECM, Lues R, Farber JM, Parreira VR. SARS-CoV-2 and Risk to Food Safety. Frontiers in Nutrition. 2020;7:243.

[23] Heller L, Mota CR, Greco DB. COVID-19 faecal-oral transmission: Are we asking the right questions? Science of the Total Environment. $2020 ; 729$.

[24] Zhan J, Liu QS, Sun Z, Zhou Q, Hu L, Qu G, et al. Environmental impacts on the transmission and evolution of COVID-19 combing the knowledge of pathogenic respiratory coronaviruses. Environmental Pollution. 2020;267.

[25] Van Doremalen N, Bushmaker T, Morris DH, Holbrook MG, Gamble A, Williamson BN, et al. Aerosol and surface stability of SARS-CoV-2 as compared with SARS-CoV-1. New England Journal of Medicine. 2020;382(16):1564-7.

[26] Ebere E, Wirnkor V, Wang Q, Yadav D, Isiuku B, Chowdhury M, et al. Indirect Exposure to Novel Coronavirus (SARS-CoV-2): An Overview of Current Knowledge2020. 
[27] Chin A, Chu J, Perera M, Hui K, Yen H-L, Chan M, et al. Stability of SARS-CoV-2 in different environmental conditions. medRxiv. 2020:2020.03.15.20036673.

[28] Fears AC, Klimstra WB, Duprex P, Hartman A, Weaver SC, Plante KC, et al. Comparative dynamic aerosol efficiencies of three emergent coronaviruses and the unusual persistence of SARS-CoV-2 in aerosol suspensions. medRxiv: the preprint server for health sciences. 2020:2020.04.13. 20063784.

[29] Chia PY, Coleman KK, Tan YK, Ong SWX, Gum M, Lau SK, et al. Detection of air and surface contamination by SARS-CoV-2 in hospital rooms of infected patients. Nature Communications. 2020;11(1):2800.

[30] Liu Y, Ning Z, Chen Y, Guo M, Gali NK, Sun L, et al. Aerodynamic analysis of SARS-CoV-2 in two Wuhan hospitals. Nature. 2020;582(7813):557-60.

[31] Wang Y, Yuan Y, Wang Q, Liu C, Zhi Q, Cao J. Changes in air quality related to the control of coronavirus in China: Implications for traffic and industrial emissions. Science of The Total Environment. 2020;731: 139133.

[32] Xu Y, Li X, Zhu B, Liang H, Fang C, Gong $Y$, et al. Characteristics of pediatric SARS-CoV-2 infection and potential evidence for persistent fecal viral shedding. Nature Medicine. 2020;26(4):502-5.

[33] Biryukov J, Boydston JA, Dunning RA, Yeager JJ, Wood S, Reese AL, et al. Increasing Temperature and Relative Humidity Accelerates Inactivation of SARS-CoV-2 on Surfaces. mSphere. 2020;5(4):e00441-20.

[34] Casanova LM, Jeon S, Rutala WA, Weber DJ, Sobsey MD. Effects of air temperature and relative humidity on coronavirus survival on surfaces. Applied and environmental microbiology. 2010;76(9):2712-7.

[35] Aboubakr HA, Sharafeldin TA, Goyal SM. Stability of SARS-CoV-2 and other coronaviruses in the environment and on common touch surfaces and the influence of climatic conditions: A review. Transboundary and Emerging Diseases. 2020.

[36] Cheng VCC, Wong SC, Chuang VWM, So SYC, Chen JHK, Sridhar S, et al. The role of community-wide wearing of face mask for control of coronavirus disease 2019 (COVID-19) epidemic due to SARS-CoV-2. Journal of Infection. 2020;81(1):107-14.

[37] Amoatey P, Omidvarborna H, Baawain MS, Al-Mamun A. Impact of building ventilation systems and habitual indoor incense burning on SARS-CoV-2 virus transmissions in Middle Eastern countries. Science of the Total Environment. 2020;733.

[38] Dai H, Zhao B. Association of the infection probability of COVID-19 with ventilation rates in confined spaces. Building Simulation. 2020.

[39] Chirico F, Sacco A, Bragazzi NL, Magnavita N. Can air-conditioning systems contribute to the spread of SARS/MERS/COVID-19 infection? Insights from a rapid review of the literature. International Journal of Environmental Research and Public Health. 2020;17(17):1-11.

[40] DeLeo PC, Huynh C, Pattanayek M, Schmid KC, Pechacek N. Assessment of ecological hazards and environmental fate of disinfectant quaternary ammonium compounds. Ecotoxicology and Environmental Safety. 2020;206.

[41] Interim guidance for environmental cleaning in non-healthcare facilities exposed to SARS-CoV-2 - ActiMaris [Internet]. ActiMaris. 2020 [cited 8 November 2020]. Available from: https://www.actimaris.com/interimguidance-for-environmental-cleaning-in-non-healthcare-facilitiesexposed-to-sars-covcov-2/?lang=en

[42] Dev Kumar G, Mishra A, Dunn L, Townsend A, Oguadinma IC, Bright $\mathrm{KR}$, et al. Biocides and Novel Antimicrobial Agents for the Mitigation of Coronaviruses. Frontiers in Microbiology. 2020;11.

[43] WHO, FAO. Benefits and risks of the use of chlorine-containing disinfectants in food production and food processing : report of a joint FAO/WHO expert meeting, Ann Arbor, MI, USA, 27-30 May 2008. Geneva: World Health Organization; 2009. 
[44] Gharpure R, Hunter CM, Schnall AH, Barrett CE, Kirby AE, Kunz J, et al. Knowledge and practices regarding safe household cleaning and disinfection for COVID-19 prevention - United States, May 2020. Morbidity and Mortality Weekly Report. 2020;69(23):705-9.

[45] Singh A. Covid-19: Disinfectants and sanitisers are changing microbiomes. The BMJ. 2020;370.

[46] Ejtahed HS, Hasani-Ranjbar S, Siadat SD, Larijani B. The most important challenges ahead of microbiome pattern in the post era of the COVID-19 pandemic. Journal of Diabetes and Metabolic Disorders. 2020.

[47] Getahun H, Smith I, Trivedi K, Paulin S, Balkhy HH. Tackling antimicrobial resistance in the COVID-19 pandemic. Bulletin of the World Health Organization. 2020;98(7).

[48] Hora PI, Pati SG, McNamara PJ, Arnold WA. Increased Use of Quaternary Ammonium Compounds during the SARS-CoV-2 Pandemic and Beyond: Consideration of Environmental Implications. Environmental Science \& Technology Letters. 2020:acs.estlett.0c00437.

[49] Kampf G, Todt D, Pfaender S, Steinmann E. Corrigendum to "Persistence of coronaviruses on inanimate surfaces and their inactivation with biocidal agents" [J Hosp Infect 104 (2020) 246-251] (Journal of Hospital Infection (2020) 104(3) (246-251), (S0195670120300463), (10.1016/j.jhin.2020.01.022)). Journal of Hospital Infection. 2020; 105(3):587.

[50] Kratzel A, Todt D, V'kovski P, Steiner S, Gultom ML, Thao TTN, et al. Efficient inactivation of SARS-CoV-2 by WHO-recommended hand rub formulations and alcohols. bioRxiv. 2020:2020.03.10.986711.

[51] WHO, Safety WHOP. WHO guidelines on hand hygiene in health care. Geneva: World Health Organization; 2009.

[52] Ma QX, Shan H, Zhang HL, Li GM, Yang RM, Chen JM. Potential utilities of mask-wearing and instant hand hygiene for fighting SARS-CoV-2. Journal of medical virology. 2020.

[53] WHO. SAVE LIVES - Clean Your Hands [Internet] [cited 2 November 2020]. Available from: https://www.who.int/infection-prevention/campaigns/cleanhands/5moments/en/.

[54] Cavanagh G, Wambier CG. Rational hand hygiene during the coronavirus 2019 (COVID-19) pandemic. Journal of the American Academy of Dermatology. 2020;82(6):e211.

[55] Koo JR, Cook AR, Park M, Sun Y, Sun H, Lim JT, et al. Interventions to mitigate early spread of SARS-CoV-2 in Singapore: a modelling study. The Lancet Infectious Diseases. 2020;20(6):678-88.

[56] Subbaraman N. 'Distancing is impossible': refugee camps race to avert coronavirus catastrophe. Nature. 2020;581(7806):18.

[57] Wang J, Yang W, Pan L, Ji JS, Shen J, Zhao K, et al. Prevention and control of COVID-19 in nursing homes, orphanages, and prisons. Environmental Pollution. 2020;266.

[58] Network Characteristics and Visualization of COVID-19 Outbreak in a Large Detention Facility in the United States - Cook County, Illinois, 2020, Figure 2, High Resolution Graphics.69(44).

[59] Wang Y, Tian H, Zhang L, Zhang M, Guo D, Wu W, et al. Reduction of secondary transmission of SARS-CoV-2 in households by face mask use, disinfection and social distancing: a cohort study in Beijing, China. BMJ Global Health. 2020;5(5).

[60] Murphy N, Boland M, Bambury N, Fitzgerald M, Comerford L, Dever N, et al. A large national outbreak of COVID-19 linked to air travel, Ireland, summer 2020. Euro Surveill. 2020;25(42).

[61] Mesa Vieira C, Franco OH, Gómez Restrepo C, Abel T. COVID-19: The forgotten priorities of the pandemic. Maturitas. 2020;136:38-41.

[62] WHO. Advice on the use of masks in the context of COVID-19: interim guidance, 6 April 2020. Geneva: World Health Organization; 2020 2020. Contract No.: WHO/2019-nCov/IPC_Masks/2020.3. 
[63] Using face masks in the community. Using face masks in the community [Internet] [cited 20 November 2020]. Available from: https://www.ecdc. europa.eu/en/publications-data/using-face-masks-community-reducingcovid-19-transmission\#no-link.

[64] Matuschek C, Moll F, Fangerau H, Fischer JC, Zänker K, van Griensven $\mathrm{M}$, et al. Face masks: benefits and risks during the COVID-19 crisis. European journal of medical research. 2020;25(1):32.

[65] Matuschek C, Moll F, Fangerau H, Fischer JC, Zänker K, Van Griensven $\mathrm{M}$, et al. The history and value of face masks. European Journal of Medical Research. 2020;25(1).

[66] Lyu W, Wehby GL. Community Use Of Face Masks And COVID-19: Evidence From A Natural Experiment Of State Mandates In The US. Health affairs (Project Hope). 2020;39(8):1419-25.

[67] Maclntyre CR, Chughtai AA. Facemasks for the prevention of infection in healthcare and community settings. BMJ : British Medical Journal. 2015;350:h694.

[68] Beesoon S, Behary N, Perwuelz A. Universal masking during COVID-19 pandemic: Can textile engineering help public health? Narrative review of the evidence. Preventive Medicine. 2020;139.

[69] Konda A, Prakash A, Moss GA, Schmoldt M, Grant GD, Guha S. Aerosol Filtration Efficiency of Common Fabrics Used in Respiratory Cloth Masks. ACS Nano. 2020;14(5):6339-47.

[70] STA znanost: Study shows efficacy of cloth masks ranging from $19 \%$ to 82\% [Internet]. Znanost.sta.si. 2020 [cited 19 November 2020]. Available from: http://znanost.sta.si/2831009/study-shows-efficacy-ofcloth-masks-ranging-from-19-to-82

[71] Lustig SR, Biswakarma JJH, Rana D, Tilford SH, Hu W, Su M, et al. Effectiveness of Common Fabrics to Block Aqueous Aerosols of Viruslike Nanoparticles. ACS Nano. 2020;14(6):7651-8.

[72] Desai AN, Aronoff DM. Masks and Coronavirus Disease 2019 (COVID-19). JAMA - Journal of the American Medical Association. 2020; 323(20):2103.

[73] Liu X, Zhang S. COVID-19: Face masks and human-to-human transmission. Influenza and other Respiratory Viruses. 2020;14(4):472-3.

[74] Akber Abbasi S, Khalil AB, Arslan M. Extensive use of face masks during COVID-19 pandemic: (micro-)plastic pollution and potential health concerns in the Arabian Peninsula. Saudi Journal of Biological Sciences. 2020.

[75] Food safety risk during the pandemic. Food Science and Technology. 2020;34(2):14-7. 